\title{
Carcinoma larynx in a 10-year-old girl: a rare clinical entity
}

\author{
Md Zahidul Islam', Shaikh Muniruddin Ahmad², Md. Mahmudul Huda ${ }^{3}$
}

\begin{abstract}
:
Childhood carcinoma larynx is a very rare clinical entity. A girl of 10 year-old presented with persistent and progressive sore throat with dysphagia, change of voice and respiratory distress with stridor which needed tracheostomy and nasogastric tube feeding. Indirect laryngoscopy revealed exophytic growth involving the epiglottis and ary-epiglottic folds, restricted movement of hemilarynx and compromised airway. Biopsies were positive for squamous cell carcinoma. The malnourished cachectic poor patient was referred for receiving radiotherapy. A high index of suspicion is necessary to make the diagnosis since consequences of late diagnosis are very serious. This report underscores the need for prompt evaluation of children with persistent and progressive sore throat with dysphagia.
\end{abstract}

Key word: Childhood carcinoma larynx, laryngeal carcinoma.

\section{Introduction:}

The first documented case of laryngeal cancer in a child was reported by Rehn in 1868 in a 3 year-old child ${ }^{1}$. For more than a century thereafter, only 54 cases of laryngeal carcinoma have been reported in children 15 years of age or younger ${ }^{2}$. Only, before this case is being reported, 22 cases in patients 10 year- old or younger and 63 cases in patients 15 year-old or younger have been reported up to date since $1868^{2-12}$.

1. Department of Otolaryngology - Head \& Neck Surgery, Dhaka Medical College Hospital. Dhaka, Bangladesh.

2. Registrar. Department of Otolaryngology Head \& Neck Surgery, Dhaka Medical College Hospital. Dhaka, Bangladesh.

3. MD (Histopathology- part III), Bangabandhu Sheikh Mujib Medical University. Dhaka, Bangladesh.

Address of Correspondence: Dr. Md Zahididul Islam, Department of Otolaryngology - Head \& Neck Surgery, Dhaka Medical College Hospital. Dhaka, Bangladesh.
Nevertheless, physicians must be aware that a small percentage of cases do occur in the pediatric age group since case reports in patients less than 15 years of age, laryngeal cancers accounts for less than $0.1 \%$ of all head and neck malignancies ${ }^{13}, 14,15$. In a survey of 98 cases of carcinoma of the larynx in patients less than 20 years of age, have about 20 cases in the 12 and under age group ${ }^{3}$. However, the incidence of female patients is higher in childhood $(40 \%$ of childhood cases vs. less than $10 \%$ of adult cases) ${ }^{5}$, and risk factors, except previous irradiation of papilloma, papillomatosis, malnutrition, are rare. Adolescent carcinomas also appear to be linked to immunologic and genetic factors rather than more common risk factors such as tobacco use, previous radiation, and chemical carcinogens found in adult patients ${ }^{16,17}$. Malignant degeneration can take place in juvenile papillomatosis which was found by a study to be more common in children who had had radiotherapy 
for papillomatosis; consequently the practice of irradiating these children has been abandoned ${ }^{3}$. Among the other reported risk factors for laryngeal carcinoma are papillomatosis of the larynx, laryngopharyngeal reflux, human immunodeficiency virus (HIV) infection, immunosuppressive therapy, exposure to drug use during pregnancy, both active and passive smoking, exposure to certain chemicals (e.g. asbestos), alcohol use, poor oral hygiene, and a family history of cancer; ${ }^{18}$ so, attempt for HPV viral subtyping, search for $\mathrm{p} 16$ and $15: 19$ translocation with not neglecting the HIV should be made for aetipathogenesis. Younger patients tend to have a long history of progressive airway obstruction, dysphagia, or dysphonia; but lesions are not recognized until an otolaryngologist is consulted for a fiberoptic airway examination and a delay in diagnosis attributed to the erroneous attribution of some common paediatric respiratory and voice problems and difficult paediatric examination makes the problem more complicated. The scarcity of cases, attempt to preserve anatomy and function of larynx and for avoidance of complications impedes establishment of treatment protocols in children. All authors agree that a primary work up should consist of detailed radiological imaging endoscopy with biopsy, and possible tracheostomy for airway protection and, thereafter, definitive management of squamous cell carcinoma in pediatric patients has varied based on the individual circumstance of the patient ${ }^{19}{ }^{20}$. Prognosis of childhood laryngeal cancer is unclear since the reported survival rates are not tumor stage related.

\section{Case report:}

A 10-year-old malnourished girl had attended in the Deptt. of ENT - Head \& Neck Surgery, Sher-e-Bangla Medical College Hospital, Barisal, with sore throat, dysphagia, change of voice and respiratory distress. The sore throat was persistent and progressive in nature for about two months, the dysphagia was also persistent and progressive over one month, progressive hoarseness of voice over two weeks and lastly the respiratory distress over one week associated with stridor for 3 days which necessitated tracheostomy and nasogastric tube feeding.

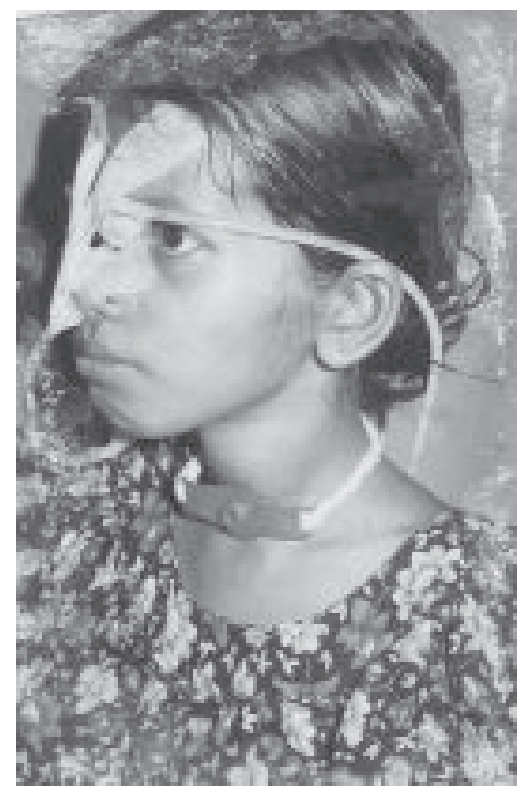

Figure 1: A 10-year-old tracheostomized girl with carcinoma larynx

The Indirect laryngoscopic examination revealed a globular exophytic growth involving the epiglottis left $A E$ fold and anterior part of the right $A E$ fold. Left vocal cord could not be seen but movement of the left hemilarynx was found restricted with compromised airway. There was no palpable neck node and no systemic metastasis found. The patient was appeared malnourished and cachectic with anemia. Systemic examination did not reveal any noticeable abnormalities. In Direct laryngoscopic examination, the globular exophytic growth in the larynx was assessed and staged as $\mathrm{T}_{3} \mathrm{~N}_{\mathrm{O}} \mathrm{M}_{\mathrm{O}}$. 


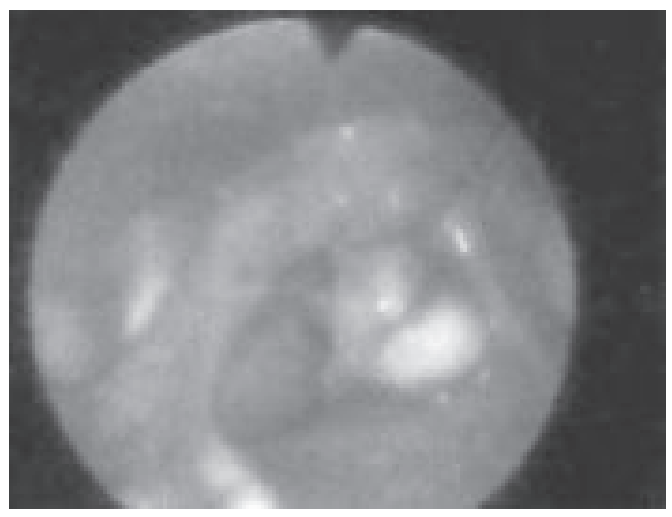

Figure 2: Endoscopic view of laryngeal carcinoma.

Tissue was taken from the growth for histopathological examination and that revealed well differentiated squamous cell carcinoma (SCC). The patient was referred to NICRH, Mohakhali, Dhaka, for oncological management.

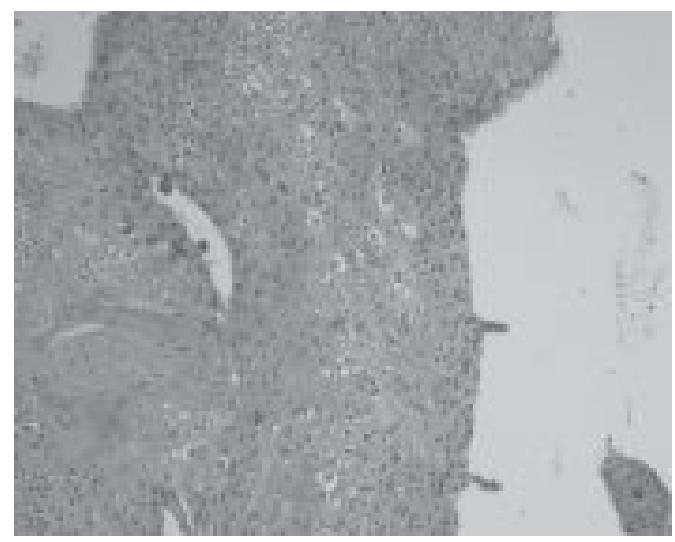

Figure 3: Histopathological section displays feature of squamous cell carcinoma in biopsy from laryngeal lesion.

Due to the personal, financial and communication problem, patient could not afford her treatment. Within two weeks following diagnosis, the girl became more cachectic and ultimately died of cardiopulmonary failure.

\section{Discussion:}

Carcinoma larynx is an old-age malignancy. In children, the common laryngeal neoplasm is laryngeal papillomatosis. The most common age of carcinoma larynx is around $6^{\text {th }}$ decade of life ${ }^{21}$. In Bangladesh, mean age at presentation of supraglottic carcinoma is $35-80$ years $^{22,23} .90 \%$ of laryngeal carcinoma is squamous cell carcinoma and its different variant ${ }^{21}$. Among the laryngeal carcinoma, supraglottic carcinoma appears earlier in adult population. Supraglottic carcinoma is common laryngeal carcinoma of this subcontinent compared to the western population. This is found more among the younger age group in low socioeconomic group with less male/female ratio in the developing country ${ }^{22,23}$.

Clinical manifestations of laryngeal carcinoma in adolescents may include hoarseness or cough, which may be mistaken for common respiratory infections, pre-pubertal voice change, or other benign childhood conditions ${ }^{24}$. Recurrent respiratory tract infection, or asthma, vocal abuse, difficult examination in children makes the case more aggressive and ultimately fatal ${ }^{16,17}$. Due to its rarity, tendency to mimic benign conditions and the relative difficulty of the pediatric laryngeal examination, SCC is not usually considered in the differential diagnosis of persistent hoarseness or cough, which may lead to a delay in diagnosis. Vocal folds are the most common site of involvement by SCC in adolescents, followed by supraglottic and then subglottic locations ${ }^{25}$.

Etio-pathological basis for childhood and adolescence carcinoma larynx is postulated being irradiation for papillomatosis, HPV infection, HPV induced genome mutation, chromosomal translocation ${ }^{18}{ }^{21}$. The relationship of HPV to laryngeal carcinoma is unclear although some studies have attributed laryngeal irradiation as a 
predisposing factor in the development of carcinoma. Until the 1970s, malignant degeneration of recurrent respiratory papillomatosis [RRP] was seen in association with patients that underwent radiation therapy for their disease. Spontaneous malignant degeneration of RRP has been reported in the laryngotracheal and bronchioalveolar regions with an incidence rate of $2.3 \%^{26}$. Regarding HPV subtyping, HPV 11 had been linked to the malignant transformation of juvenile-onset $\mathrm{RRP}^{27}$. Malignant transformations of papillomatosis were $14 \%$ (6 of 43 irradiated cases) before 30 years of age whereas no transformation was reported in 58 similar cases treated with surgery alone ${ }^{28}$. Some study relates the risk factors like geographical distribution, malnutrition, and social classes since majority of supraglottic carcinoma cases were from lower socioeconomic group ${ }^{22,23}$. The differential diagnosis of laryngeal neoplasm in children includes: papilloma, subglottic hemangiomas, squamous carcinoma, rhabdomyosarcoma, and adenocarcinoma of minor salivary gland.

In this study 10-year-old female child with carcinoma larynx is so far the first reported case in this country. The postulated causes of our case are HPV infection along with factors like malnutrition and effect of secondary smoking or other environmental oncogenic factors. Due to unfamiliarly of this disease among the physician and pediatricians, she was diagnosed in an advanced stage. Aggressiveness of the disease process, malnutrition, lack of medical support, financial constrain, communication inconvenience, she could not get proper and early intervention which caused her unfortunate fatal outcome.

\section{Conclusion:}

Childhood laryngeal carcinoma is very rare malignant condition. The etiology of this disease is not exactly known. Clinical features are aggressive and the outcome is poor since the diagnosis and the treatment is always late. In any suspected cases where some risk factors are associated should be dignified. Although unusual, one should have a high index of suspicion for any hoarseness, cough, or upper airway disease that does not respond to appropriate medical treatment. By reporting this case and highlighting the difficulties in diagnosis and treatment we hope to increase clinical awareness and thus lead to an improved outcome. Accurate and early diagnosis of the childhood laryngeal carcinoma with prompt aggressive treatment is essential.

\section{References:}

1. Cunningham MJ, McGuirt WF and. Myers EN, Malignant tumors of the head and neck. In: CD. Bluestone, SE. Stool and MA. Kenna, Editors, Pediatric otolaryngology (3rd ed.), Saunders, Philadelphia, 1996; 1557.

2. Gindhart TD, Johnston WH and. Chism SE et al. Carcinoma of the larynx in childhood. Cancer 1980; 46: 1683-1687.

3 Ohlms LA, McGill $T$ and Healy GB.Malignant laryngeal tumors in children: A 15-year experience with four patients, Ann Otol Rhinol Laryngol 1994; 103: 686.

4. Rehn H. Cancer of the vestibule and vocal cords in a 3-year-old boy. Arch Pathol Anat Physiol Klin Med 1868; 43: 129-133.

5. Zuckerman JD, Shehata BM, Hill CH \& Sobol SE. (2009). Invasive laryngeal carcinoma in a 15-year-old boy with neglected papillomatosis. The Internet Journal of Otorhinolaryngology 2009; 8: $32-5$. 
6. Nsamba C, Marrocco G. Carcinoma of the Larynx in a Child. J Laryngol Otol 1989; 93: 89-92.

7. Ossoff RH, Tucker GF and Norris CM. Carcinoma of the larynx in a 11-yearold boy. Otolaryngol Head Neck Surg 1980; 88 (2): 142-145. View Record in Scopus | Cited By in Scopus (10).

8. Orton HB. Carcinoma of the larynx. Clinical report of a case - age $131 / 2$ years. Laryngoscope 1947; 57: 299_ 303.

9. Laurian N, Sadov R, Strauss M, Kessler E. Laryngeal carcinoma in childhood. Report of a case and review of the literature. Laryngoscope 1984; 94(51): 684-7.

10. Zalzal GH, Cotton RT, Bove K. Carcinoma of the larynx in a child. Int $\mathrm{J}$ Pediatr Otorhinolaryngol 1987; 13(2): 219-25.

11. Singh $W$ and Kaur A. Laryngeal carcinoma in a 6 year old with a review of the literature, J Laryngol Otol 1987; 101 (9): 957-958.

12. Simon M, Kahn T, Schneider A and Pirsig W. Laryngeal carcinoma in a 12-yearold child. Association with human papilloma virus 18 and 33, Arch Otolaryngol Head Neck Surg 1994; 120 : 277-282. View Record in Scopus | Cited By in Scopus (24)

13. Rastogi $M$, Srivastava $M$, Bhatt MLB, et al. Laryngeal carcinoma in a 13-yearold child. Oral Oncol Extra 2005; 41: 207-10.

14. Jones AC. Carcinoma of the larynx in a girl aged 15. Arch Otol 1942; 35: 426430.

15. McGuirt WF, Little JP. Laryngeal cancer in children and adolescents,
Otolaryngology Clinics of North America 1997; 30: 207-214.

16. Faragó L. \& Nagy A. A rare case of malignant degeneration of a childhood laryngeal papilloma. Mschr Ohrenheilk 1966; 100: 131-135.

17. Rutt AL, Hawkshaw MJ, Sataloff RT. Laryngeal cancer in patients younger than 30 years: a review of 99 cases. Ear Nose Throat J 2010; 89(4): 189-92.

18. Ossoff RH, Tucker GF, Norris CM.Carcinoma of the larynx in an 11 year old boy with late cervical metastasis: report of a case with ten year follow-up, Otolaryngology Head and Neck Surgery 1980; 88: 142-145.

19. Brasilino de Carvalho et al. Head and Neck Squamous Cell Carcinoma in Childhood. Medical and Pediatric Oncology1998; 31: 96-99.

20. Birchall MA and Pope L. Tumours of the larynx. Scott-Brown's Otorhinolaryngology, Head and Neck Surgery, 7th edition, editor: Michael Gleeson, Edward Arnold. 2008; 194: 2598-2622.

21. Walkinson JC, Gaze MN, Wilson JA. Tumours of the larynx. Stell and Maran's, Head and Neck Surgery, $4^{\text {th }}$ ed; Butlerworth Heinemann, Oxford 2000; 15: 233-273.

22. Hossain MA, Ahmed SMTU, Alam MM, Tarafder $\mathrm{KH}$, Humayun AHMP. Presenting features of supraglottic carcinoma of larynx. Bangladesh J Otorhinolaryngol 2010; 16: 106-112.

23 McDermott A, Raj P, Glaholm J, et al. De novo laryngeal carcinoma in childhood. J Laryngol Otol. 2000; 114(4): 293-5.

24. Kitcher ED, Yarny J, Gyasi RK \& Cheyuo C. Laryngeal Cancer at the Korle 
Bu Teaching Hospital Accra Ghana. Ghana Medical Journal 2006; 40: 45-49.

25. Gaylis B, Hayden RE. Recurrent respiratory papillomatosis: progression to invasion and malignancy. American Journal of Otolaryngology 1991;12:104112.

26. Moore CE, Wiatrak BJ, McClathey KD, Koopman CF, Thomas GR, Bradford CR, Carey TE. High-risk human papillomavirus types and squamous cell carcinoma in patients with respiratory papilloma. Otolaryngology Head and Neck Surgery 1999; 120(5): 698-705.

27. French C, Kutok J, Faquin W, et al. Midline carcinoma of children and young adults with NUT rearrangement. J Clin Oncol 2004; 22: 4135-9.

28. Majoros M, Devine KD and Parkhill EM. Malignant transformation of benign laryngeal papilloma in children after radiation therapy. Surg Clin North Am 1963; 43: 1049-1061. 